\title{
Transmission of walnut-feeding skills from mother to young in wood mice (Apodemus speciosus)
}

\author{
Reina Takechi, Fumio Hayashi* \\ Department of Biology, Tokyo Metropolitan University, Hachioji, Tokyo, Japan. \\ Email: "
}

Received 14 September 2011; revised 24 October 2011; accepted 18 November 2011.

\begin{abstract}
Mammalian feeding behavior is often acquired or improved by learning. Social learners are thought to attain novel information or skills faster and at lower cost than asocial learners. In this study, we examined what types of learning affect the acquisition of efficient feeding behavior by the wood mouse Apodemus speciosus when feeding on large, hard-shelled walnuts. In house cages, naïve mice acquired an efficient feeding manner during the 14-day conditioning to walnuts, suggesting individual trial-and-error learning contributes to their feeding skills. Social factors such as learning from walnuts that have been opened by other individuals or by observing walnut consumption by proficient conspecifics did not affect the rate of acquisition of efficient feeding. However, weaned offspring could eat walnuts more efficiently and frequently if the mother had been given walnuts during her rearing period. Thus, the skill is likely transmitted between the mother and offspring in addition to individual self-learning.
\end{abstract}

Keywords: Cultural Transmission; Feeding Skills; Maternal Effects; Rodent; Self-Learning; Social Learning

\section{INTRODUCTION}

Behavioral improvement with experience is the result of learning. Although learning is often thought of as an individual exercise, in nature, much learning is social, i.e., under the influence of conspecifics. Typically, social learners acquire novel information or skills faster and at lower cost than self-learners [1]. Social learning can be defined as learning from social information and learning through social interactions. Different species have different mechanisms of learning from social information, ranging from selective attention to the environment due to the presence of others to copying of complete sequences. In vertical social learning, naïve individuals often learn skills or knowledge from parents, whereas horizontal social learning is from peers, either immature or adult individuals, and often involves eavesdropping. Because vertical social learning is usually adaptive, mature individuals often prefer it to individual exploration [1].

Japanese walnuts, Juglans ailanthifolia Carrière, are highly nutritious seeds that are covered by an extremely hard shell. On mainland Honshu, Japan, because of the hard shell, major consumers of the walnut are Japanese squirrels, Sciurus lis Temminck, and Japanese wood mice, Apodemus speciosus (Temminck) [2,3]. Although the wood mice (20 - $60 \mathrm{~g}$ in body weight) are smaller than the squirrels $(250-310 \mathrm{~g})$ [4], they either eat the walnuts immediately after finding them or after hoarding them [5]. The mice gnaw holes in the shell and then pick the meat from the holes. One to $3 \mathrm{~h}$ is required for a mouse to eat the meat from one side of the nut, even if the shell is gnawed continuously. The positioning of the hole is a key factor in the ability to eat the meat without being obstructed by the inner partition wall and without leaving the meat in the deep portion of the nut [6]. Eating from a hole in the raphe of the shell is the most efficient strategy, whereas holes in other parts of the shell are less effective. Experience is likely to contribute to the development of walnut-feeding skills because 1) mice captured from habitats with walnut trees tend to consume nuts more efficiently than mice from habitats without the trees, and 2) artificially supplementing walnuts in a natural habitat results in an increased number of mice with efficient feeding skills [6]. Such behavioral modification by experience implies that the mice are able to learn walnut-feeding skills.

The purpose of this study was to determine how the mice learn efficient walnut feeding. In the wild, individual walnut-feeding skills are likely acquired through 1) trial-and-error, 2) from walnuts that have been opened by other individuals, 3) observing nut consumption by proficient conspecifics, or 4) the mother before natal dispersal. To examine processes 1) - 3), the feeding behaviors for consuming intact walnuts were compared among four 
groups. For the first group, in which another individual had efficiently opened the walnuts, nuts were provided to all mice simultaneously. For the second group, a walnut with a small artificial hole at an appropriate position was given to each mouse simultaneously. For the third group, demonstrators were placed nearby the feeding mice, while the fourth (control) group was not provided with opened walnuts or demonstrators. In these observations, to avoid any confounding effects of experience with walnuts in the wild before the laboratory experiments, we used a population from Izu-Oshima Island (naïve to walnuts) because no walnut trees occur on this island. Finally, to examine learning process 4), field-caught pregnant females with efficient walnut-feeding skills were divided into two rearing groups. The first group was provided with walnuts continuously until offspring became independent, whereas the second group had no access to walnuts just after the birth of the offspring. The mice hoard and eat walnuts in their underground nest sites [5]. Therefore, both experimental situations may occur in the field. The former conditions may provide the offspring a chance to learn walnut feeding, whereas this is not the case in the latter. Thus, this final experiment tested for the occurrence of vertical social learning from the mother.

\section{MATERIALS AND METHODS}

\subsection{Observations of the Control Group}

The study site was on Izu-Oshima Island $\left(34^{\circ} 45^{\prime} \mathrm{N}\right.$, $\left.139^{\circ} 22^{\prime} \mathrm{E}\right)$, located $108 \mathrm{~km}$ south of Tokyo, Japan. A 2.5$\mathrm{km}^{2}$ study site was established in a forest on the southern part of this island. The main tree species were Castanopsis cuspidata, Persea thunbergii, Cryptomeria japonica, and Alnus sieboldiana. The main understory species included Camellia japonica, Aucuba japonica, and Pseudosasa japonica. The walnut trees are not native to this island [7].

Mice were live-trapped using approximately 50 Sherman traps (Folding Trap-LFA, $230 \times 75 \times 90$ mm; H. B. Sherman Traps, Tallahassee, FL, USA) from February to October in 2006 and from May 2009 to May 2010. The traps were covered with vinyl and fixed to the substrates on the ground with wire. Peanuts and cotton were provided in the traps as food and nest material, respectively. The traps were set in the late afternoon and recovered at dawn in the next morning. Lactating females were released immediately at the capture sites. All other captured mice were taken to the laboratory with carrying cages $(240 \times 155 \times 145$ mm; Sanko Shokai Co. Ltd, Osa$\mathrm{ka}$, Japan) in which peanuts, a piece of apple, water, and cotton were supplied. After mice were sexed, weighed, and assessed for reproductive state, they were placed in individual cages $(200 \times 250 \times 350 \mathrm{~mm})$. Each cage was partitioned with screen, so that mice could not see each other. A transparent plastic box $(70 \times 70 \times 200 \mathrm{~mm})$ was used as the nest site. This box included wood shavings and had two entrance holes. One or two small, dead twigs (20 $\mathrm{mm}$ in diameter, $250 \mathrm{~mm}$ long) were also placed in the cages to simulate natural habitats. One peanut and five sunflower seeds were supplied daily. Rodent pellets (Hamster and Lis Lunch; Hipet Co. Ltd, Osaka, Japan) were also added daily at an amount representing $10 \%$ of the body weight of the mouse. Water was provided ad libitum. A small piece of apple was supplied on days 1 - 3, and half of a small dried sardine was supplied on days 6 and 10 as supplemental food. Mice were reared under nearly natural temperature and day length conditions except that the temperature was prevented from exceeding $28^{\circ} \mathrm{C}$ in the summer. After the observations were complete, the mice were released at their original capture sites after clipping a single toe to mark individuals to avoid repeated usage of the mice.

Walnuts were collected in the field at Chiyoda, Ibaraki Prefecture, and stored under dark, cool conditions until use. On each day of the experiment, one walnut was randomly chosen and placed in each mouse cage (Figure 1(a)) in the evening after it was weighed and measured (maximum height, width, and thickness). We used $\pi$ (height $\times$ width $\times$ thickness $) / 6$ as an indicator of walnut volume $\left(\mathrm{mm}^{3}\right)$. All nuts were recovered the following day, and their position in the cage and all signs of feeding were noted. This trial was repeated for 14 consecutive days after mice were captured. Half of a cracked walnut was supplied to each mouse on the 15th day, and we checked whether the meat had been eaten the following day. Feeding behaviors were divided into five grades: intact (including slightly moved nuts), hoarded, gnawed, eaten on one side, and eaten on two sides. If walnuts were eaten, we distinguished between efficient and inefficient feeding based on the feeding marks. The time from the beginning of gnawing to the end of eating was determined using a video camera (Digital Handycam models: DCR-TRV 17, DCR-TRV 30, DCR-PC 300, DCR-HC 90, or DCR-HC 96; Sony, Tokyo, Japan). This feeding time excluded resting time, during which mice ceased feeding for more than $1 \mathrm{~min}$. Behavior at night was videotaped under weak light ( $<1.0$ lux).

The feeding skill development was divided into four categories and scored as follows: A, when a mouse ate the meat from a hole on the raphe (i.e., efficient feeding) from the beginning of the 14-day observation period; $\mathrm{B}$ when efficient feeding occurred after several inefficient feedings; B' if feeding was still inefficient on the 14th day, and $\mathrm{C}$ if the mouse never consumed the walnut meat during the observation period. 


\subsection{Learning from Feeding Signs and Demonstrators}

To examine the effect of feeding signs on the feeding behavior, the mice of this experimental group (Ex. 1) were given an additional walnut every day, one side of which was opened and eaten by a proficient mouse, while the other side remained intact (Figure 1(b)). The walnuts with efficient feeding signs were derived from previous experiments [6] using the mice from the Tama Forest Science Garden, Hachioji, Tokyo $\left(35^{\circ} 39^{\prime} \mathrm{N}, 139^{\circ} 16^{\prime} \mathrm{E}\right)$, and Yugashima, the Izu Peninsula, Shizuoka Prefecture $\left(34^{\circ} 52^{\prime} \mathrm{N}, 138^{\circ} 54^{\prime} \mathrm{E}\right)$. The feeding behavior was observed in the same manner as for the above-mentioned control group.

In addition, to examine the effect of feeding signs, the mice of the second experimental group (Ex. 2) were given an additional walnut that had been artificially opened on one side using a steel rasp and the meat left in (Figure 1(c)). The methods of observation were the same as Ex. 1.

For the third experiment (Ex. 3), the feeding behavior of the mice with demonstrators was monitored in the same way as described above to examine whether mice learn feeding more efficiently by observing walnut consumption by proficient conspecifics (Figure 1(d)). In this experiment, six mice ( 2 males, 4 females) captured in March 2006 from the Yugashima population, which open walnuts efficiently, were used as demonstrators. Cages containing the object mouse and the demonstrator were placed within $10 \mathrm{~mm}$ of one another to allow the mice to observe each other. During the 14-day monitoring period, the demonstrators fed on an average of 5.2 walnuts $(N=20, \mathrm{SD}=3.5)$ and the proportion of efficient feedings was $62.4 \%(N=20, \mathrm{SD}=33.6)$.

An analysis of variance (ANOVA) was used to compare the body weights of mice, the volume of nuts, the weight of nuts, and the feeding times. A Kruskal-Wallis test was used to compare the number of nuts and the proportion of efficient feedings because the data were unlikely to be normally distributed.

\subsection{Learning from Mothers}

Fifteen pregnant females collected in the field from September 2005 to May 2010 that were confirmed to eat walnuts efficiently within the first 14-day monitoring period were used in this experiment. The walnut-available group was supplied with walnuts throughout the period, whereas for the walnut-unavailable group, walnuts were not provided once the mice produced offspring. The former group contained eight females: three from the Tama Forest Science Garden, three from Yugashima, one from Izu-Oshima, and one from Kakegawa (Shizuoka; $\left.34^{\circ} 77^{\prime} \mathrm{N}, 138^{\circ} 01^{\prime} \mathrm{E}\right)$. The latter group contained seven females: two from the Tama Forest Science Garden, one from Kazuma (Tokyo; $35^{\circ} 73^{\prime} \mathrm{N}, 139^{\circ} 04^{\prime} \mathrm{E}$ ), one from Yugashima, two from Izu-Oshima, and one from Kakegawa.

Field-caught females were placed in individual cages $(200 \times 250 \times 350 \mathrm{~mm})$. During the first 14 days, the rearing and observation methods were the same as in the control group. After that, we continued to provide one walnut every day until offspring were produced, which was easily determined by their squeaks. After birth, one group of females was provided with a walnut everyday (walnut-available group), while the other group was not given any walnuts (walnut-unavailable group) (Figure 1(e)). By 26 - 35 days after birth, which was determined to be approximately 2 weeks after the first day that offspring moved out of the nest, offspring were separated from the mother and reared individually in new cages $(100 \times 200 \times 300 \mathrm{~mm})$. At this time, the body weight of each offspring was measured. For the walnut-available group, the mother consumed $16-33$ walnuts $(N=8,24.5$ $\pm 6.0 \mathrm{SD}$ ) during the pup-rearing period, and the proportion of efficient feedings was $88.1 \%(N=8, \mathrm{SD}=11.5)$. The feeding behavior of these offspring was monitored for 30 days during which one whole walnut was given on 1 day, then recovered on the following day for examination (Figure 1(e)). On the 31st day, half of a cracked walnut was supplied to each mouse, and whether the meat had been eaten was checked the following day. Once the individual offspring were able to eat walnuts in an efficient manner, monitoring was stopped and the body weight at this time was measured. The mice that failed to eat walnuts were weighed at the end of monitoring (31st day).

A $t$-test was used to compare the data between the two groups unless the variances were not equal, in which case Welch's approximate $t$ was used [8].

\section{RESULTS}

\subsection{Feeding Behavior of the Control Group}

Thirty-one mice were monitored regarding their feeding behavior for 14 days. The mean body weight of mice was $35.4 \pm 8.0 \mathrm{~g}(N=31)$. The sex ratio (proportion of males) was $0.42(13 / 31)$. The supplied walnuts were $14.2 \times 10^{3}$ $\pm 0.4 \mathrm{~mm}^{3}(N=31)$ in volume and $9.15 \pm 0.18 \mathrm{~g}(N=31)$ in weight. Of a total of 14 walnuts, $5.3 \pm 3.8(N=31)$ were intact, $3.3 \pm 3.7(N=31)$ were gnawed, and $1.0 \pm$ $1.8(N=31)$ were eaten. Eight of $31(25.8 \%)$ mice were observed to eat walnut meat at least once. When the walnuts were eaten, the proportion of efficient feedings was $57.1 \pm 35.4 \%(N=8)$. The feeding time was $130.9 \pm$ $33.9 \min (N=8)$. On the 15 th day, the meat of the cracked walnuts was eaten by all 31 mice. 
(a)

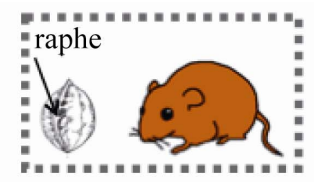

(b)

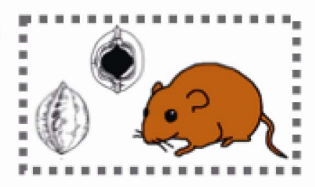

(c)

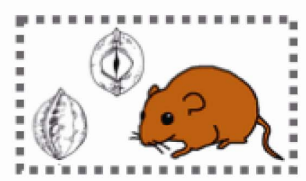

(e)
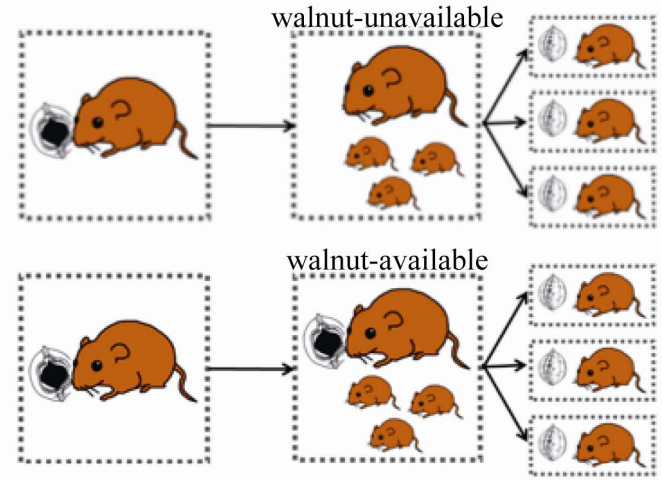

(d)

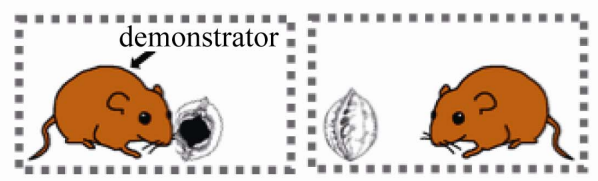

Figure 1. Schematic drawings of the study designs and treatments of the mice for examining the effects of feeding signs and demonstrators: (a) Control; (b) Experiment 1; (c) Experiment 2; (d) Experiment 3; (e) examining social learning between the mother and offspring. If opened at the central part of raphe, mice can eat walnuts efficiently. Only intact walnuts were given in the Control, whereas walnuts opened on one side by other proficient mice or by using a steel rasp were provided in Experiments 1 and 2, respectively. In Experiment 3, proficient mice were placed close to the experimental mice. In the mother-offspring experiment, once the offspring were produced, one group was provided a walnut every day (walnut-available group), while the other group was not given any walnuts (walnut-unavailable group).

\subsection{Effects of Feeding Signs and Demonstrators}

The feeding behaviors were examined for each of the 20 mice in the three experimental groups, and the results were compared among four groups including the control. The body weight of mice differed significantly among the groups (Figure 2(a); ANOVA, $F_{3.87}=2.78, P=0.01$ ). The sex ratio was similar among the groups: 11 males and 9 females in Ex. 1, 10 males and 10 females in Ex. 2, and 13 males and 7 females in Ex. 3 (chi-square test: $\chi_{3}^{2}$ $=2.71, P=0.44$ ). The mean size of walnuts supplied to the mice was approximately $14 \times 10^{3} \mathrm{~mm}^{3}$ (range 13.7$14.4 \times 10^{3} \mathrm{~mm}^{3}$ ), although it differed significantly among the four groups (Figure 2(b); ANOVA, $F_{3.87}=11.61, P$ $<0.001)$. The mean weight of the nuts ranged from 9.07 to $9.15 \mathrm{~g}$, but did not differ among the groups (ANOVA, $F_{3.87}=1.31, P=0.28$ ).

The number of intact walnuts did not differ significantly among the four groups (Figure 2(c): Kruskal-Wallis test, $H_{3}=4.44, P=0.22$ ). Neither the number of nuts gnawed and/or eaten nor the number of nuts eaten differed among the groups (Figure 2(d): Kruskal-Wallis test, $H_{3}=1.25, P=0.74$; Figure 2(e): Kruskal-Wallis test, $\left.H_{3}=2.10, P=0.55\right)$. The proportion of the four feeding patterns (A, B, B', and C) did not differ significantly among the control group and Experiments 1 - 3 (Figure 3(a)). Due to the small proportion of each feed- ing pattern, the combined proportions of $\mathrm{A}, \mathrm{B}$, and $\mathrm{B}$ ' (the proportion of mice that could eat the nuts) were statistically compared among the groups: 8 of $31(25.8 \%), 2$ of $20(10.0 \%), 6$ of $20(30.0 \%)$, and 2 of $20(10.0 \%)$ for the Control, Ex. 1, Ex. 2, and Ex. 3, respectively. This difference was not significant (chi-square test: $\chi_{3}^{2}=$ $4.44, P=0.22)$. Even if the walnuts were eaten, the proportion of efficient feedings (Figure 2(f); Kruskal-Wallis test, $H_{3}=1.52, P=0.68$ ) and the feeding time (Figure 2(g); ANOVA, $\left.F_{3.10}=1.09, P=0.40\right)$ did not differ significantly among the groups.

For the mice in Ex. 1, walnuts with feeding marks (one side not eaten) were available in addition to a fresh one (Figure 1(b)). During the 14 days, nine of 20 (45.0\%) mice gnawed these marked walnuts ( 1 - 9 nuts/individual), and two $(10.0 \%)$ mice ate the uneaten side of the marked walnuts (one ate one nut and the other ate five nuts). However, their feeding manner was always inefficient and no fresh nuts, which were given simultaneously, were eaten. For the mice in Ex. 2, walnuts with an artificially made small hole (one side only) were also available (Figure 1(c)). During 14 days, 17 of $20(85.0 \%)$ mice gnawed these holed walnuts ( 1 - 14 nuts/mouse), and five $(25.0 \%)$ mice ate the un-holed side of the walnuts ( 1 - 5 nuts/mouse). The proportion of efficient feedings on the un-holed side of walnuts was $34.7 \%(N=5$, 

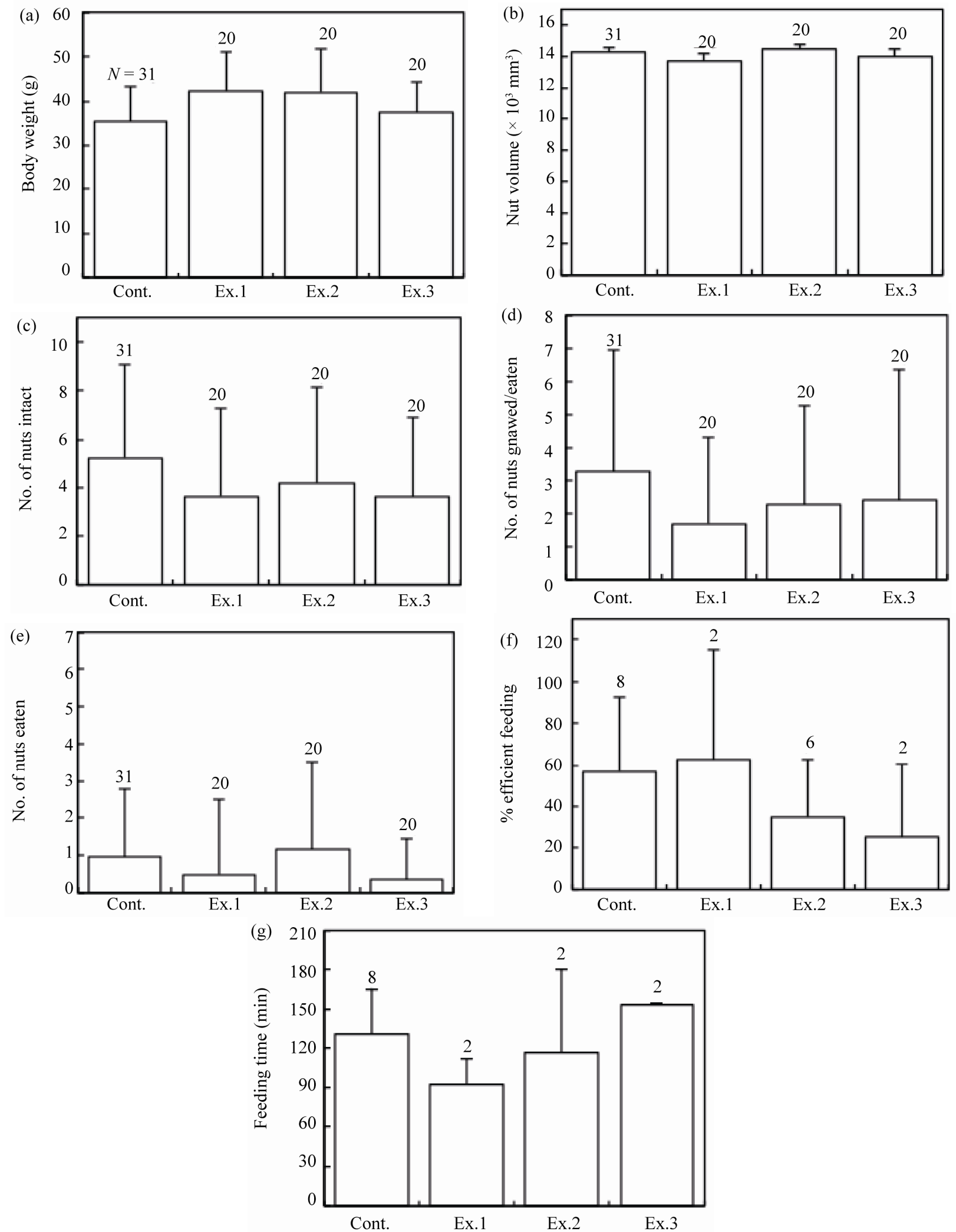

Figure 2. Effects of feeding signs produced by other mice (Ex. 1), those opened using a steel rasp (Ex. 2), and the demonstrators (Ex. 3 ) on the feeding behavior (c)-(g) of the target mice. The body weight of the mice (a) and the walnut size given (b) are also shown. $N$ indicates the number of mice examined. Bars indicate \pm SD. 

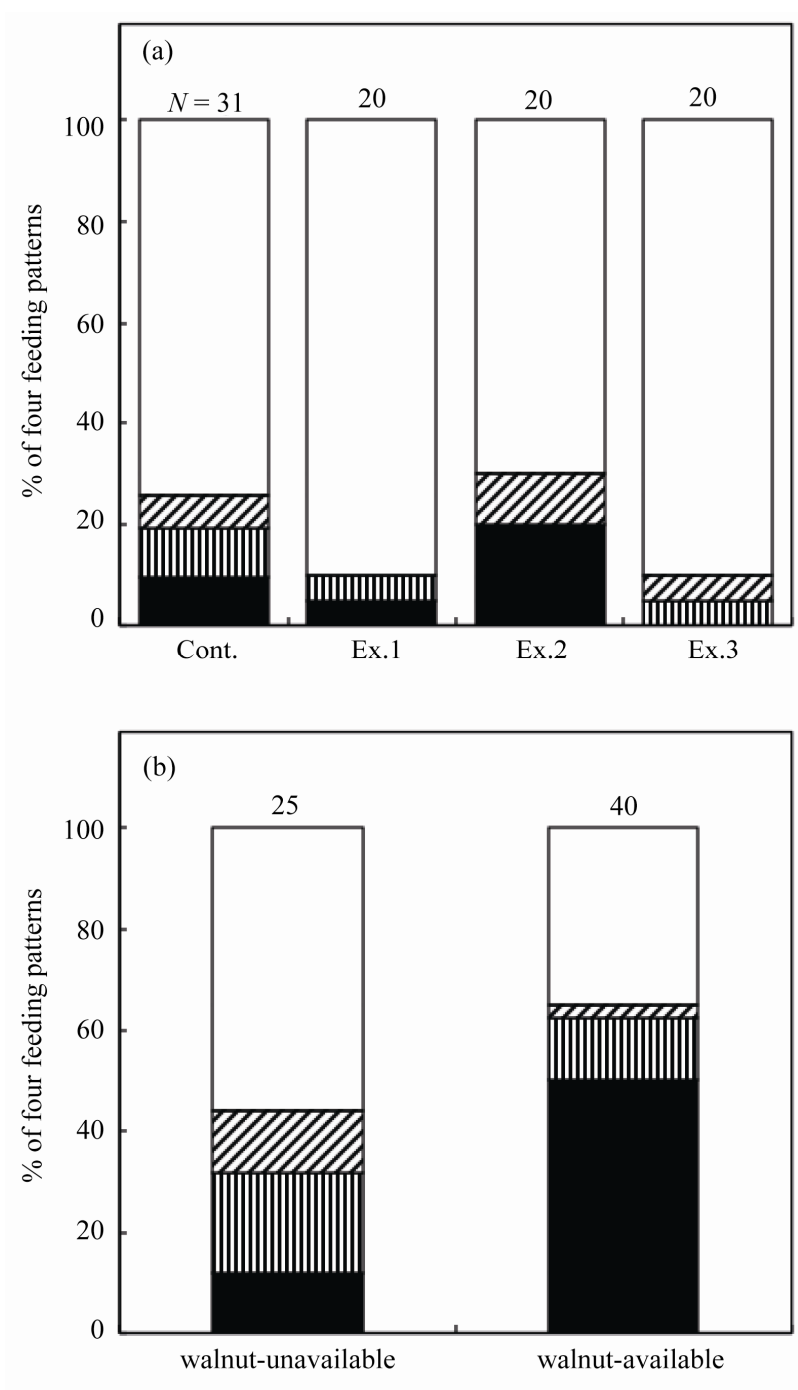

Feeding patterns:

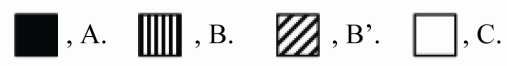

Figure 3. The proportion of mice with four feeding patterns of walnuts in the Control, Experiment 1 (adding walnuts with a feeding sign), Experiment 2 (adding walnuts with an artificial hole), and Experiment 3 (seeing demonstrators) after a 14-day training period (a), and in walnut-unavailable and available conditions when the mother was rearing pups (b). Feeding pattern A involves eating the meat from the hole on the raphe from the beginning of the 14-day observation period, while $\mathrm{B}$ represents efficiently eating the meat after several inefficient feedings; B' remains inefficient after 14 days, and $\mathrm{C}$ indicates that the mice never ate the meat during the observation period. $N$ is the number of mice examined.

$\mathrm{SD}=41.0$ ). However, three of these five mice never ate the fresh nuts that were given simultaneously.

On the 15th day, all mice ate the meat of the cracked nuts in Experiments 1 - 3, which was the same result for the control group.

\subsection{Learning from the Mother}

The mean litter size was $3.6(N=7, \mathrm{SD}=1.1)$ and $5.0(N$ $=8, \mathrm{SD}=2.1)$ for the walnut-unavailable and available mothers, respectively. This difference was not significant ( $t$-test, $\left.t_{13}=2.16, P=0.14\right)$. Twenty-five (14 males, 11 females) and 40 pups (17 males, 23 females) were obtained from the walnut-unavailable and available groups, respectively. The sex ratio did not differ significantly between the two groups (chi-square test; $\chi_{1}^{2}=1.12, P$ $=0.29$ ). The pups were separated from the mother to start monitoring their feeding behavior at 31.6 days old $(N=25, \mathrm{SD}=2.3)$ and $20.7 \mathrm{~g}(N=25, \mathrm{SD}=5.7)$ for the walnut-unavailable group and 32.4 days old $(N=40, \mathrm{SD}$ $=2.0)$ and $19.8 \mathrm{~g}(N=40, \mathrm{SD}=4.0)$ for the walnutavailable group. The age and weight at the onset of monitoring did not differ between the two groups ( $t$-tests; $t_{63}$ $=2.00, P=0.10$, and $t_{39}=1.68, P=0.48$, respectively). The volumes and weights of the walnuts used to monitor the pups' feeding behavior were $12.4(N=25, \mathrm{SD}=0.5)$ $\times 10^{3} \mathrm{~mm}^{3}$ and $11.9(N=40, \mathrm{SD}=0.5) \times 10^{3} \mathrm{~mm}^{3}$ in the walnut-unavailable and available groups, respectively ( $t$-test, $\left.t_{63}=3.57, P=0.0007\right)$, and $8.24 \mathrm{~g}(N=25, \mathrm{SD}=$ $0.19)$ and $8.21 \mathrm{~g}(N=40, \mathrm{SD}=0.17)$ in the walnut-unavailable and available groups, respectively ( $t$-test, $t_{63}=$ $0.65, P=0.52$ ).

The proportions of pups scored as A, B, B', and C during the monitoring period differed significantly between the walnut-unavailable and available groups (Figure 3(b)) (chi-square test; $\chi_{2}^{2}=9.92, P=0.004$ ). Pups that fed efficiently from the beginning (scored as A) increased when reared by the mother that was provided with walnuts. The pups at the first efficient nut-consumption were 44.9 days old $(N=8, \mathrm{SD}=7.4)$ and 28.8 $\mathrm{g}(N=8, \mathrm{SD}=4.9)$ in the walnut-unavailable group and 44.4 days old $(N=25, \mathrm{SD}=8.6)$ and $27.3 \mathrm{~g}(N=23, \mathrm{SD}$ $=5.2)$ in the walnut-available group. These values did not differ between the two groups ( $t$-tests; $t_{31}=1.70, P=$ 0.90 , and $t_{29}=1.70, P=0.49$ for age and weight, respectively).

On the last monitoring (30th) day, 17 and 15 pups were still unable to efficiently eat the walnuts in the walnut-unavailable and available groups, respectively. These failed pups were 63.0 days old $(N=17, \mathrm{SD}=1.8)$ and $31.8 \mathrm{~g}(N=17, \mathrm{SD}=6.9)$ in the walnut-unavailable group and 63.9 days old $(N=15, \mathrm{SD}=1.7)$ and $30.0 \mathrm{~g}$ $(N=15, \mathrm{SD}=6.3)$ in the walnut-available group. The age and weight of these pups did not differ significantly between the two groups ( $t$-tests; $t_{30}=1.38, P=0.18$, and $t_{30}=0.77, P=0.45$, respectively). On the 31 st day, all pups ate the walnut meat from the cracked nut. 


\section{DISCUSSION}

To gain access to the walnut meat, the mice gnaw the hard shell while holding the nut on the ground with both paws. This appears to be a difficult task as approximately $2 \mathrm{~h}$ was required for a mouse to finish gnawing through the shell and eating the meat from one side of the nut, even if the attempt was continuous. Walnut trees are not distributed on Izu-Oshima Island [7]. Walnuts appeared to be the preferable food items, even for the mice on this island, because they all consumed the meat when cracked nuts were provided. However, only a few individuals managed to eat the walnuts. In the control group, $25.8 \%$ of mice were able to eat the nuts during the 14-day period, suggesting that the mice were able to improve their feeding techniques via individual trial-and-error learning. This type of self learning has been reported for other rodent species including Eurasian red squirrels (Sciurus vulgaris) feeding on hazelnuts [9], the Japanese squirrel (Sciurus lis) feeding on walnuts [10], Norway rats (Rattus norvegicus) feeding on mollusks inhabiting a river bottom [11,12], and Algerian mice (Mus spretus) feeding on acorns without weevil infestation [13].

Social factors are also important in the development of feeding behavior. To the extent that a naïve animal can use the behavior of other individuals to guide the development of its own behavioral repertories, it should be able to acquire adaptive responses to environmental demands without incurring all of the costs of individual trial-and-error learning [14]. For example, black rats (Rattus rattus) that have experience removing the scales from a pinecone that has been partially opened by either another rat or a human experimenter become proficient extractors of seeds $[15,16]$. The black rat can also acquire pinecone-stripping techniques through cultural transmission from the dam to its pups [15,16]. In American red squirrels, Tamiasciurus hudsonicus, naïve captive individuals learn to open hickory nuts by watching conspecifics complete the task [17]. Here, we examined whether mice learn from encountering walnuts that have been opened either by other individuals or artificially, and from observing nut consumption by proficient conspecifics. We found no significant effect of these factors on the improvement of feeding behavior. In some rodent species, younger individuals are better able to learn from demonstrators than older ones $[10,18,19]$; however, examining this characteristic in A. speciosus was difficult because the immature period was very short compared to the training period.

In the mother-offspring experiments, offspring were able to eat walnuts more efficiently when reared by the walnut-consuming mothers, which suggests that social learning between the mother and offspring is effective for transmitting efficient walnut-feeding skills. In our experiment, however, an alternative explanation may apply that does not involve social learning. The offspring of the mice whose mother opened walnuts throughout their nursing and weaning period would have been familiar with the walnuts; they would have manipulated them as well as consumed the kernel extracted by their mothers, and thus would know that walnuts are a good food source. Thus, these youngsters might be more motivated to attempt opening the walnuts themselves. Conversely, the offspring of the mothers that did not receive walnuts would be less motivated to attempt to open the walnut during the tests. The difference in motivation could affect whether the youngsters approach and manipulate the walnuts, which in turn could affect whether they are able to learn to efficiently open them.

Although the mechanism behind mother-offspring interactions is still unclear, the experimental situations used in this study may be similar to field conditions. Female mice rear their offspring in underground nests, where the mother stores walnuts in the autumn for later consumption [5]. In central Japan, these mice experience two reproductive seasons, one in early summer and one in late autumn [4]. The late-autumn breeding in particular fits our experimental situations because the mother eats stored walnuts during the rearing period. In Apodemus rodents, females tend to settle near the natal site while males tend to disperse far away [20]. The transmission of feeding skills from the mother to daughters may be more important than that from a mother to sons because the sons cannot transmit the skill to other individuals or to the next generation. In contrast, daughters with efficient feeding skills have a good chance of reproducing near the mother's range (i.e., within the vicinity of walnut trees), and thus their skills would be useful for the next generation. This may explain why a high proportion $(92 \%)$ of walnuts are efficiently opened in the field [6].

\section{ACKNOWLEDGEMENTS}

We thank Tadashi Suzuki and Tamotsu Kusano for valuable discussion on various aspects of this study. The capturing of mice was permitted by the Tokyo, Shizuoka, and Chiba prefectural governments. All rearing and experimental procedures were approved by the Tokyo Metropolitan University Animal Ethics Committee. This study was partially supported by Research Fellowships of the Japan Society for the Promotion of Science for Young Scientists (21-7638) to R. Takechi.

\section{REFERENCES}

[1] Van Schaik, C.P. (2010) Social learning and culture in animals. In: Kappeler, P. Ed., Animal Behaviour: Evolution and Mechanisms, Springer, Berlin, 623-653. doi:10.1007/978-3-642-02624-9 20

[2] Kato, J. (1985) Food and hoarding behavior of Japanese 
squirrels. Japanese Journal of Ecology, 35, 13-20.

[3] Miguchi, H. (1993) Ecological features of seed dispersion by rodents. In: Kawanabe, H., Washitani, I. and Ohgushi, T. Eds., Interaction of Animals and Plants. In Japanese, Heibonsha, Tokyo, 236-253.

[4] Abe, H., Ishii, N., Kaneko, Y., Maeda, K., Miura, S. and Yoneda, M. (1994) A Pictorial Guide to the Mammals of Japan. In Japanese, Tokai University Press, Tokyo.

[5] Tamura, N. (2001) Walnut hoarding by the Japanese wood mouse, Apodemus speciosus Temminck. Journal of Forest Research, 6, 187-190. doi:10.1007/BF02767091

[6] Takechi, R., Tamura, N. and Hayashi, F. (2009) Improved walnut-feeding skills with experience in wood mice, Apodemus speciosus. Journal of Ethology, 27, 8389. doi:10.1007/s10164-008-0087-y

[7] Oshima-shizen-aikoukai (2000) Mijikanimirareru IzuOshima no shokubutsu. In Japanese, Oshima-cho, Tokyo.

[8] Zar, J.H. (1999) Biostatistical analysis. 4th Edition, Prentice Hall, Upper Saddle River.

[9] McFarland, D. (1981) The Oxford companion to animal behaviour. Oxford University Press, Oxford.

[10] Tamura, N. (2011) Population differences and learning effects in walnut feeding technique by the Japanese squirrel. Journal of Ethology, 29, 351-363. doi:10.1007/s10164-011-0267-z

[11] Gandolfi, G. and Parisi, V. (1973) Ethological aspects of predation by rats, Rattus norvegicus (Berkenhout), on bivalves, Unio pictorum L. and Cerastoderma lamarcki (Reeve). Bollettino di Zoologia, 40, 69-74. doi:10.1080/11250007309427482

[12] Parisi, V. and Gandolfi, G. (1974) Further aspects of the predation by rats on various mollusc species. Bollettino $d i$ Zoologia, 41, 87-106. doi:10.1080/11250007409430096

[13] Muñoz, A. and Bonal, R. (2008) Seed choice by rodents: Learning or inheritance? Behavioral Ecology and Sociobiology, 62, 913-922. doi:10.1007/s00265-007-0515-y

[14] Galef, B.G.Jr. (2007) Social learning in rodents. In: Sherman, P.W. and Wolff, J. Eds., Rodents Societies. University of Chicago Press, Chicago, 207-215.

[15] Ainser, R. and Terkel, J. (1992) Ontogeny of pine cone opening behaviour in black rats, Rattus rattus. Animal Behaviour, 44, 327-336. doi:10.1016/0003-3472(92)90038-B

[16] Zohar, O. and Terkel, J. (1996) Social and environmental factors modulate the learning of pine-cone stripping techniques by black rats, Rattus rattus. Animal Behaviour, 51, 611-618. doi:10.1006/anbe.1996.0065

[17] Weigl, P.D. and Hanson, E.V. (1980) Observational learning and the feeding behavior of the red squirrel Tamiasciurus hudsonicus: The ontogeny of optimization. Ecology, 6, 213-218. doi:10.2307/1935176

[18] Garef, B.G.Jr. (1980) Diving for food: Analysis of a possible case of social learning in wild rats (Rattus norvegicus). Journal of Comparative Physiology, 94, 416-425.

[19] Terkel, J. (1996) Cultural transmission of feeding behavior in the black rat (Rattus rattus). In: Heyes, C.M. and Galef, B.G.Jr. Eds., Social Learning in Animals. Academic Press, New York, 17-47.

[20] Ohnishi, N., Saitoh, T. and Ishibashi, Y. (2000) Spatial genetic relationships in a population of the Japanese wood mouse Apodemus argenteus. Ecological Research, 15, 285-292. doi:10.1046/j.1440-1703.2000.00348.x 